\title{
Early Experience With Soft Hydrogel Lens Implants
}

\author{
S. P. B. PERCIVAL \\ Scarborough
}

\begin{abstract}
Summary
A new material which more closely mimics the properties of living tissue than polymethylmethacrylate is under investigation. Twelve hydrogel lenses were placed into the ciliary sulcus following the standard nucleus extraction technique and 38 were placed into the lens capsule using the endocapsular technique. Six months following surgery 66 per cent of sulcus fixated lenses were found to have both haptics in the sulcus and 76 per cent of capsule fixated lenses were found to have both haptics encapsulated. The hydrogel lens was found to be well tolerated within the eye with 32 per cent of eyes achieving a visual acuity of $6 / 5$ and 94 per cent achieving $6 / 12$ or better.
\end{abstract}

It is now standard practice in the treatment of cataract for the human lens to be replaced by an artificial lens, which is intended usually to be sited within the membranous capsule from which the cataract was removed. Polymethyl methacrylate (PMMA) was the material recommended by Harold Ridley, inventor and pioneer of the lens implant ${ }^{1}$ and is still used by the vast majority of lens implant manufacturers, because it has withstood the test of time ${ }^{2}$ and is inert within the eye.

However, PMMA has two disadvantages. The first is that unlike any ocular tissue, it is hard and brittle. As a lens implant, it is difficult for it to be accommodated by the minute alterations of size and shape that occur between individual eyes or within the same eye during the course of a day. Incorporation of flexibility into the lens design may be associated with low grade inflammatory syndromes, ${ }^{3,6}$ although total placement within the lens capsule reduces the inflammatory response. ${ }^{4.5}$ But it is not always possible to be certain of total placement and if the lens is not encapsulated, there is, apart from inflam- mation, the risk of decentration and other morbidity. ${ }^{4-8}$

The second disadvantage of PMMA is its non-wettable hydrophobic property causing toxicity to living cells with which it may come into contact, notably the corneal endothelium and the iris pigment epithelium. Serious complications of lens implants, such as bullous keratopathy, ${ }^{9,10}$ iris chafing ${ }^{11}$ and pigment dispersion glaucoma ${ }^{12}$ may be attributed to this.

New materials which more closely mimic the properties of living tissue therefore deserve investigation. One such material is the hydrogel poly 2-hydroxyethyl methacrylate (P-HEMA). In its hydrated state, this contains 38 per cent water and is hydrophilic, soft and flexible. Research ${ }^{13-18}$ has shown P-HEMA to be inert and biocompatible with intraocular tissue. There is little or no damage to endothelial cells on contact with the cornea ${ }^{15-17}$ and no inflammatory response on prolonged contact with the iris. ${ }^{14}$

However, it remains to be seen how its qualities as a lathe cut intraocular lens measure up to those of the traditional PMMA

Correspondence to: Mr S. P. B. Percival, Department of Ophthalmology, Scarborough General Hospital, Scarborough YO12 6QL.

Presented at the Annual Congress of the Ophthalmological Society of the United Kingdom, April 1987. 
lens in the long term and to this end a clinical trial was set up at Scarborough. This communication reports on the results of the first 50 such lenses implanted.

\section{Material and Methods}

The P-HEMA lens used was that pioneered and described by Barrett. ${ }^{18}$ It is a single piece bioconvex lens of $6 \mathrm{~mm}$ diameter supported in a solid haptic $0.2 \mathrm{~mm}$ thick and overall $12 \mathrm{~mm}$ long but gently curving forwards.

Patients were entered into the trial at random, criteria being age over 65 years and the absence of past uveitis, glaucoma or proliferative retinopathy. The age range was $65-90$ years (mean 75 years).

Initially it was planned to insert 25 of these lenses into the ciliary sulcus and 25 into the capsular bag. However, sulcus placement was associated with uncertainty and some instability, so the plan was changed: after the first 27 implantations all subsequent implants were planned to be inserted into the capsular bag. No implantations were aborted.

Technique for sulcus insertion (12 eyes) included a clean excision of a $7 \mathrm{~mm}$ disc of anterior capsule followed by extracapsular extraction as previously described ${ }^{19}$ but without the aid of sodium hyaluronate. The technique for cataract extraction for bag placement (38 eyes) was the endocapsular method as described by Galand ${ }^{20}$ but using the irrigating vectis for extracting the lens nucleus. The hydrogel lens was slid under the anterior capsule without using any visco-elastic agents and the upper haptic was placed under the upper flap of capsule by using a simple side to side movement with a blunt dialling hook.

Six months after surgery all eyes underwent detailed examination. Pupils were dilated with cyclopentolate and phenylephrine in order to determine;

(a) Whether the edge of the lens optic extended into the central $5 \mathrm{~mm}$ pupillary zone,

(b) The position of the lens haptics with respect to the lens capsule using the Goldmann 3 mirror lens.

\section{Results}

Of those lenses intended to be placed in the ciliary sulcus, eight had both haptics in the sulcus, three had one haptic in the sulcus and one had both haptics in the bag of the capsule. Of those intended to be placed in the capsule, 29 had both haptics in the bag, seven had one haptic in the bag and one had both haptics in the sulcus. One, on the day after surgery was found to have dislocated through a break in the posterior capsule into the vitreous. Mild decentration could be detected in 6 per cent of capsule placements, in 22 per cent of sulcus placements and in 80 per cent of placements partly within the capsule. However, in only four patients was the edge of the lens optic visible in the undilated pupil and in only one of these was it the cause of symptoms.

Operative complications included one partial break of the lens zonule and three broken posterior capsules, two of these being associated with vitreous loss. Postoperative complications included three instances of uveitis which developed towards the end of the first week.

Visual acuity recorded at six months was $6 / 5$ in 32 per cent of eyes, $6 / 6$ in 42 per cent of eyes, $6 / 9$ or $6 / 12$ in 20 per cent of eyes and less than $6 / 12$ in only 6 per cent. The reasons for acuity to be less than $6 / 12$ were senile macular degeneration (one eye), presumed macular oedema associated with a ruptured posterior capsule and lens dislocation (one eye) and clinically significant lens decentration (one eye).

\section{Discussion}

In order to minimise the morbidity from lens implantation it is recommended that the implant be inserted into the existing lens capsule. However, certainty of placement is not always possible. For flexible loop posterior chamber lenses McDonnell and Green ${ }^{6}$ described a discrepancy between intended and actual placement in 65 per cent of eyes and at post mortem they found that only 6 per cent had both haptics encapsulated. The P-HEMA lens used in the current study was found to be easy to handle and ideal for the "envelope" technique of endocapsular extraction. Results show it too can have a discrepancy between intended and actual placement, as 34 per cent of sulcus placements were not found to have both haptics in the ciliary sulcus and 24 per cent of capsule placements were not found to have both haptics encapsulated. However, this included a learning period and as the insertion technique for capsule placement was modified, it was found that 100 per cent certainty of total encapsulation could be achieved in all uncomplicated cases.

The visual results from this lens were better than might be expected from the age group 
concerned with 32 per cent of patients seeing $6 / 5$ and 94 per cent seeing $6 / 12$ or better. There have, so far, been no cases of capsule fibrosis requiring capsulotomy and apart from decentration, there have been no complications which could be attributed to the lens implant.

The advantages of this hydrogel lens are that it is autoclavable, hydrophilic, resistant to mechanical stress within the eye and ideal for endocapsular surgery, without the need for visco-elastic agents. My impression is that there is a greater patient comfort than with conventional lenses with less glare and an improved cosmetic appearance. So, provided decentration can be shown not to progress in the long term, this lens should gain increasing popularity.

\section{References}

1 Ridley H: Intraocular acrylic lenses: a recent development in the surgery of cataract. $\mathrm{Br} J$ Ophthalmol 1952, 36: 113-22.

2 Drews RC: Lens Implantation: lessons from the first million. Trans Ophthalmol Soc UK 1982, 102: 505-9.

${ }^{3}$ Reidy JJ, Apple DJ, Googe JM, Richey MA, Mamalis N, Olson RJ: An analysis of semiflexible closed loop anterior chamber lenses. Am Intraocular Implant Soc J 1985, 11: 344-52.

${ }^{4}$ Miyake K, Asakura M, Kobayashi H: Effect of intraocular lens fixation on the blood aqueous barrier. Am J Ophthalmol 1984, 98: 451-5.

${ }^{5}$ Apple DJ, Reidy JJ, Googe JM, Mamalis N: A comparison of ciliary sulcus and capsular bag fixation of posterior chamber intraocular lenses. Am Intraocular Implant Soc J 1985, 11: 44-63.

${ }^{6}$ McDonnell PJ, Green WR, Champion R: Pathologic changes in pseudophakia. Seminars in Ophthalmology 1986, 1: 80-103.
${ }^{7}$ Böke WRF and Kruger HCA: Causes and management of posterior chamber lens displacement. Am Intraocular Implant Soc J 1985, 11: 179-84.

${ }^{8}$ Brems RN, Apple DJ et al.: Posterior chamber intraocular lenses in a series of 75 autopsy eyes. $J$ Cataract Refract Surg 1986, 12: 367-71.

${ }^{9}$ Bourne WM and Kaufman HE: Endothelial damage associated with intraocular lenses. $A m J$ Ophthalmol 1976, 81: 482-6.

${ }^{10}$ Cheng H: Intraocular lenses. J Roy Soc Med 1983, 76: 169-71.

${ }^{11}$ Masket S: Pseudophakic posterior iris chafing syndrome. J Cataract Refract Surg 1986, 12: 252-6.

${ }^{12}$ Smith JP: Pigmentary open angle glaucoma secondary to posterior chamber intraocular lens implantation. Am Intraocular Implant Soc J 1985, 11: 174-6.

${ }^{13}$ Chambers DW, Dillingham EO, Autian J: Toxicity testing of poly 2-hydroxyethyl methacrylate contact lens. Invest ophthalmol 1974, 13 (Supp): 43-6.

${ }^{14}$ Mehta KR, Sathe SM, Karyekar SD: The soft intraocular implant. In 6th Congress of European Society of Ophthalmology. Trevor Roper PD, ed, London, Academic Press, 1981, pp 859-63.

${ }^{15}$ Barrett GD and Constable IJ: Corneal endothelial loss with new intraocular lenses. $A m \quad J$ Ophthalmol 1984, 98: 157-63.

16 Yalon MD, Blumenthal M, Goldberg EP: Preliminary study of hydrophilic hydrogel intraocular lens implants in cats. Am Intraocular Implant Soc J 1984, 10: 315-7.

${ }^{17}$ Reich S, Blumenthal M, Sheets JW, et al.: Intraocular lens--endothelial interface: adhesive force measurements. J Biomed Materials Res 1984, 18: 737-44.

${ }^{18}$ Barrett GD, Constable IJ, Stewart AD: Clinical results of hydrogel lens implantation. J Cataract Refract Surg 1986, 12: 623-31.

${ }^{19}$ Percival SPB: Sodium Hyaluronate in cataract and intraocular lens surgery. Trans Ophthalmol Soc UK 1983, 103: 254-8.

${ }^{20}$ Galand A, van Oye E, Budo C, Goes F, Foets B Results of implantation in the Capsular Bag. Trans Ophthalmol Soc UK 1985, 104: 563-6. 